\title{
Research on Parameters in Cold Pressing Process of Swida Wilsoniana Fruits and Analysis of Its Oil
}

\author{
LIU Rukuan \\ College of Chemistry \& Chemical Engineering, Central South University, Changsha, Hunan, China \\ Li Peiwang, Xiao Zhihong, Li Changzhu, Li Hui, YI Xiaosheng \\ Hunan Academy of Forestry, Changsha, Hunan, China
}

\begin{abstract}
Swida wilsoniana is an important woody oil plant of which the whole fruits contain oils. Main contents of fruits from swida wilsoniana were analyzed through chemical means to 46 samples from different areas. These fruits have an average moisture content of about $8.19 \%$ after natural dried. The oil content is about $28.02 \%$ (dry basis) or more. The protein content is $7.25 \%$ (dry basis) and the cellulose content is about $14.18 \%$. Through theoretical calculation and the one-dimensional pressing device, the conditions of cold pressing process and performances of fruits from swida wilsoniana had been studied. The results show that swida wilsoniana fruits suffering natural dried are suitable for direct pressing, which guarantees a higher oil quality. The volume of fruits fed into pressing device had little effect on pressures of oil squeezed out , fruits crushed and critical compression, and the value of those pressures were $55.7 \mathrm{MPa}, 71.5 \mathrm{MPa}$ and $80 \mathrm{MPa}$ individually. At the critical pressure of $80 \mathrm{MPa}$ and the compression ratio of 3.14 , residual oil of meal is $6.5 \%$. The fruits oil has about $72 \%$ unsaturated fatty acids, of which approximately oleic acid is $29.83 \%$, linoleic acid is $39.15 \%$, and linolenic acid is $2.59 \%$.
\end{abstract}

KEYWORD: Swida wilsoniana; Fruits oil; Cold pressing process

Swida wilsoniana is a kind of woody oil plants[1-3] with ecological adaptability, from which the natural dried fruits contain more than $32 \%$ oil, and the average production is greater than $100 \mathrm{~kg} /\left(667 \mathrm{~m}^{2}\right)$.

Containing more than $70 \%$ unsaturated acids, fruits oil has a high nutritional value in application. The cold processing processes[4-6] with core equipment of screw or hydraulic press can guarantee the original nutrients and flavor of oils. There are few equipments suitable for special oilseeds[7-8]. It is necessary to design new type of cold pressing equipment to get high quality oil.

In order to guarantee a low temperature in the whole pressing process of fruits, this research adopted an experimental device[9] simulating diameter equidistant screw extrusion in which only pure shear extrusion. Pressures of oil squeezed out, fruits crushed and critical compression were extracted and performances of fruits in pressing process were studied by one-dimensional pressing device[10], which can provide data for the hydraulic or spiral press in cold pressing process.

\section{EXPERIMENTAL PROCEDURES}

\subsection{Materials and methods}

\subsubsection{Test materials}

Swida wilsoniana fruits, natural dried, were harvested in 2012 in Hunan Academy of Forestry. Other chemicals were of analytical grade.

\subsubsection{Testing instruments}

Fat analyzer (SZC-D): Shanghai Chubo; Infrared thermometer (DHS-120): Shanghai Jiachao; Balance (AB104-N): Mettler; Electrothermal blowing dry box (101-E): Shanghai Huayan; Centrifuge (TDL-5A): Shanghai scientific instrument factory; Circulating water vacuum pump (SHZ-D III): Gongyi Kerui; Rotary evaporator (RE52CS-1): Shanghai Yarong; Constant temperature water oscillator (HHS): Harbin Dongming Medical Instrument Factory; Acidity meter (FE20): Mettler; Gas chromatograph (GC-2014): Japan Shimadzu.

One dimensional pressing device mainly consists of the pressure rod, cylinder, filtrate plate, pressing device, a force measuring device (heavy pressure sensor) and several other components. The 
dimensions of cylinder are diameter of $20 \mathrm{~mm}$, height of $50 \mathrm{~mm}$, wall thickness of $6 \mathrm{~mm}$. The gravity sensor specifications are as follows: the range is $2 \mathrm{~T}$, voltage is $10 \mathrm{~V}(\mathrm{DC})$, the output sensitivity is $2 \mathrm{mV} / \mathrm{V}$, and the safe overload is $150 \%$. Vice specifications are model of QB 200, maximum clamping force of $34 \mathrm{KN}$, width of $200 \mathrm{~mm}$, height of $64 \mathrm{~mm}$, maximum opening of $210 \mathrm{~mm}$.
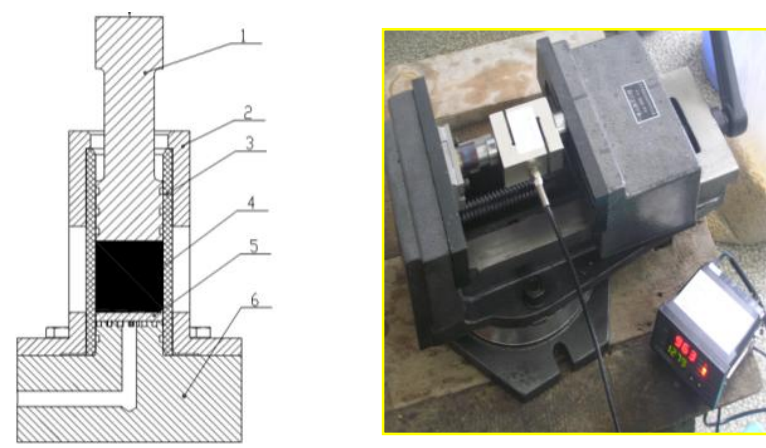

(1- plunger; 2- outer cylinder; 3-transparent tube; 4- seeds; 5permeable rock; 6- base)

Figure 1. One-dimensional pressing apparatus (the left is structure diagram, and the right is physical map)

\subsection{Test methods}

\subsubsection{Detection method of main contents of Swida wilsoniana fruits}

Oil content: GB/T 14488.1-2008; Moisture content: GB/T 5497-2008; Determination of transparency, color: GB/T 5525-2008 (colorimetric cell $25.4 \mathrm{~mm}$ ); Acid value: GB/T 5530- 2005; Saponification value: GB/T 5534-2008; Iodine number: GB/T 5532-2008; Peroxide value: GB/T 5538-2005.

\subsubsection{Analysis of fatty acid (FAMEs)}

The composition of fatty acids (FAMEs) was analysed via gas chromatography (GC-2014C, Shimadzu) via a gas chromatography column (Agilent Technologies, DM-WAX) with length of 25 $\mathrm{m}$, inner diameter of $0.3 \mathrm{~mm}$ and film thickness of $0.25 \mu \mathrm{m}$. Nitrogen was used as carrier gas. The injection was performed in a split mode with a split ratio of 100:1. The sample was injected at the injector temperature of $250{ }^{\circ} \mathrm{C}$ and a flame ionization detection temperature of $250{ }^{\circ} \mathrm{C}$. The column temperature was maintained at $180{ }^{\circ} \mathrm{C}$ for 1 min, increased at an interval of $6{ }^{\circ} \mathrm{C}$ per min to $230{ }^{\circ} \mathrm{C}$.

\subsubsection{Process of one-dimensional pressing device}

(1) Operating method

The natural-dried Swida wilsoniana fruits are added to the assembled pressing cylinder and pressed slowly. Record the conditions which are the operating time $(\mathrm{T})$, the pressing pressure $(\mathrm{P})$ and the pressing volume of oilseeds $(\mathrm{H})$.

(2) Operating conditions

Control different squeezing conditions and obtain the corresponding pressing process data. The specific operating conditions are shown in table 1.

Table 1. Conditions of one-dimensional pressing operation

\begin{tabular}{|c|c|}
\hline Operating conditions & values \\
\hline Volume of oilseeds $(\mathrm{H}, \mathrm{mm})$ & $30,35,40,45,50$ \\
\hline $\begin{array}{c}\text { Pressing pressure }(\mathrm{P}, \mathrm{MPa}) \\
\begin{array}{c}\text { Time of pressure } \\
\text { maintainences (T, min) }\end{array}\end{array}$ & $15,20,30,40,50,60,70$, \\
\hline
\end{tabular}

(3) Parameters calculation.

Pressure of oil squeezed out $\left(\mathrm{P}_{1}\right)$ is the pressure while oil is first squeezed out from swida wilsoniana fruits. Pressure of fruits crushed $\left(\mathrm{P}_{2}\right)$ is the pressure when core of swida wilsoniana fruits fractured in the press chamber. Pressure of critical compression $\left(\mathrm{P}_{3}\right)$ is the final pressure when swida wilsoniana fruits can not be compressed any more. Actual ratio of compression $(\varepsilon)$ is the ratio of the initial volume to the final volume of fruits.

\section{RESULTS AND DISCUSSION}

\subsection{Main contents of swida wilsoniana fruits and the theoretical basis of direct pressing}

Oilseeds are mainly included of fat, protein, cellulose and water, and these substances affect the physical strength of oilseeds. Swida wilsoniana fruits from different habitats and species are collected and measured by conventional chemical analysis methods for contents of crude oil, moisture, crude protein, and cellulose. Main contents of fruits from Swida wilsoniana were analyzed through chemical means to 46 samples from different areas. The fruits have an average moisture content of about $8.19 \%$ after natural dried. The oil content is about $28.02 \%$ (dry basis) or more. The protein content is $7.25 \%$ (dry basis) and the cellulose content is about $14.18 \%$.

For oilseeds, moisture content is a convenient adjustment factor, whose change will directly lead to changes of contents in oil, protein, cellulose and other indicators. Besides, physical strength will be changed. Therefore, control of moisture content of Swida wilsoniana fruits is an important means to regulate conditions of the cold pressing process. Changes of moisture content generally follow the 
rule that high temperature is suitable for low moisture content while low temperature is suitable for high moisture, and the relation between moisture content and temperature can be calculated according to the N.B. ${ }^{[11]}$ empirical formula, which is as follows

$$
c=(14-0.1 * T) * k
$$

In the above formula, $\mathrm{C}(\%)$ stands for oil content; $\mathrm{T}\left({ }^{\circ} \mathrm{C}\right)$ stands for pressing temperature; $\mathrm{k}$ stands for correction factor, which can be expressed by the formula $\mathrm{k}=(100-\mathrm{M}) / 55$, in which $\mathrm{M}(\%)$ stands for the oil content of oilseeds.

Taking a low temperature of $70 \sim 80{ }^{\circ} \mathrm{C}$, we can get the best conditioned fruits whose moisture content ranges from $7.85 \%$ to $9.16 \%$, which is just similar to the natural moisture content of fruits. So, it is suitable for Swida wilsoniana fruits to be directly fed in press, and it provides a theoretical support for us to focus on direct pressing process.

\subsection{Parameters of pressing process for oilseeds}

\subsubsection{Pressing pressure}

Figure 2 illustrates the influence of volume of oilseeds on different pressing pressure. As shown in Fig. 2, pressure of oil squeezed out $\left(\mathrm{P}_{1}\right)$ and pressure of fruits crushed $\left(\mathrm{P}_{2}\right)$ are changing slowly with the increase of oilseeds. It means amount of oilseeds have low influence on the two kinds of pressures. $\mathrm{P}_{2}$ is about $16 \mathrm{MPa}$ higher than $\mathrm{P}_{1}$. The average values of the pressure from $30 \mathrm{~mm}$ to $50 \mathrm{~mm}$ are $55.7 \mathrm{MPa}$ for $\mathrm{P}_{1}$ and $71.5 \mathrm{MPa}$ for $\mathrm{P}_{2}$.

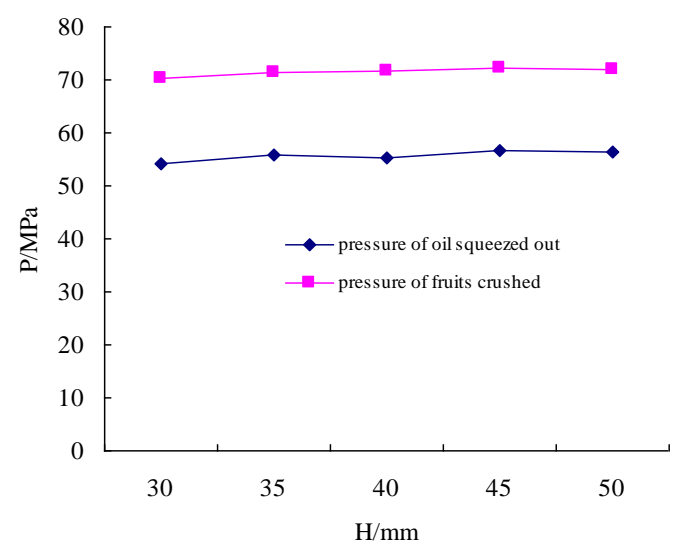

Figure 2. Influence of volume of oilseeds on different pressing pressure

\subsubsection{Pressing time}

Figure 3 illustrates influence of pressing time on compression ratio in different volume of oilseeds. The curves showed obvious changes of compression ratio with the increase of pressing time. The final compression ratios are too close which is about 3.1. With the increasing volume of oilseeds, pressing time for achieving a final uncompressed stage increases gradually. All in all, it is easy for oilseeds to achieve a relative uncompressed stage when pressed within 30 s. Through Matlab fitting, equation of relation between pressing time and volume of oilseeds ranging from $9.424 \mathrm{~cm}^{3}$ to $15.707 \mathrm{~cm}^{3}$ could be got as follows

$$
t=2.7370 V^{1}-0.0328 V^{2}-0.0011 V^{3}+0.0011 \cdots(2)
$$

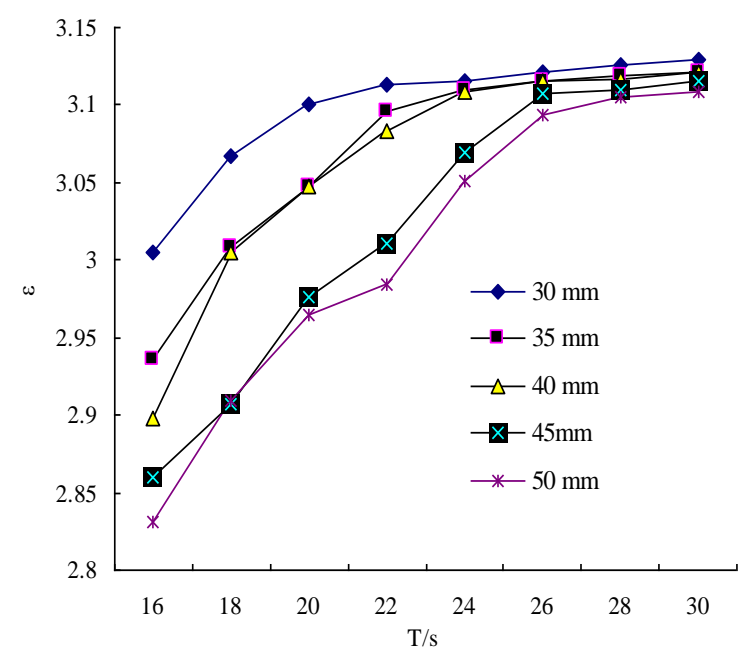

Figure 3. Influence of pressing time on compression ratio in different volume of oilseeds

\subsubsection{Actual compression ratio}

The actual compression ratio, closely related to the pressing pressure and pressing time, can directly reflect actual stage of both the oilseeds and the meal when pressed. Figure 4 illustrates the influence of pressing pressure on compression ratio in different volume of oilseeds.

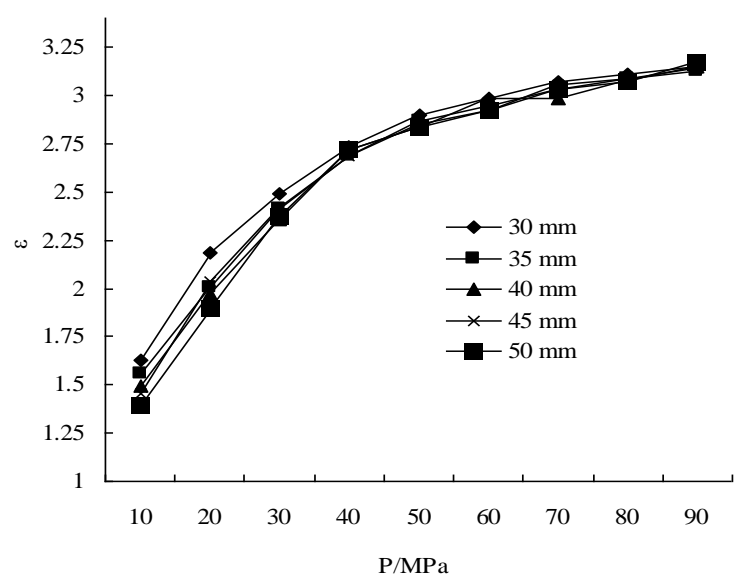

Figure 4. Influence of pressing pressure on compression ratio in different volume of oilseeds

As shown in Figure 4, curves are similar. The actual compression ratio increases with the increase of pressing pressure. But when the pressing pressure increases to a certain value, the increase of 
compression ratio is smaller, and when it reaches 80 Mpa, slope of curve is 0.0056 which means the pressing pressure has so little influence on compression ratio that can be neglected, and the oilseeds entered a non compressible phase. Taking $80 \mathrm{MPa}$ as the critical pressing pressure $\left(\mathrm{P}_{3}\right)$, the compression ratio is 3.14 and the residual oil content of meal is about $6.5 \%$ (dry basis).

\subsection{Analysis of properties of oilseeds by cold press and properties of fruits oil}

\subsubsection{Changes of main contents and forms between oilseeds and its meal}

Figure 5 shows changes of main contents between Swida wilsoniana fruits and its meal. Oil content decreases greatly from about $30 \%$ in Swida wilsoniana fruits to about $6 \%$ in the meal after being pressed. And other contents change differently. The shapes of raw oilseeds and the meal are shown in figure 6 .

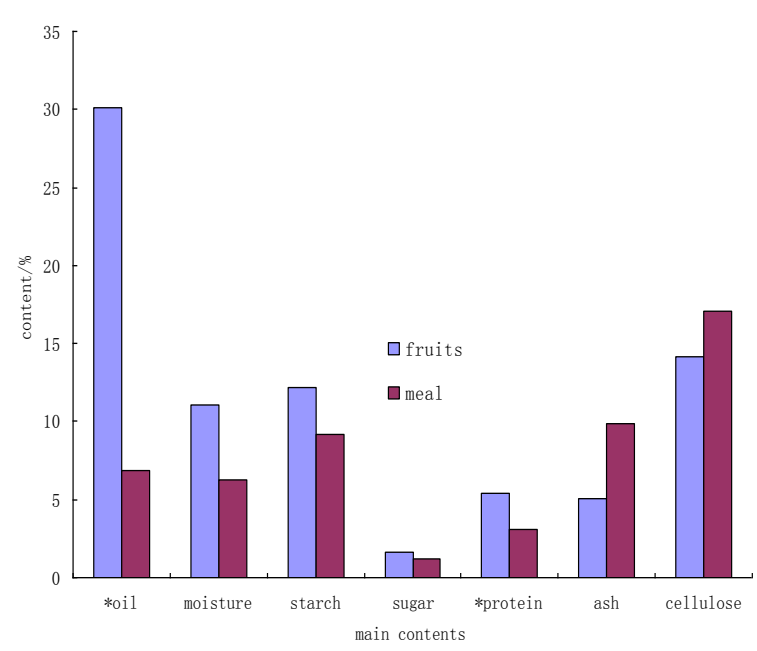

Figure 5. Comparison on main contents between Swida wilsoniana fruits and its meal
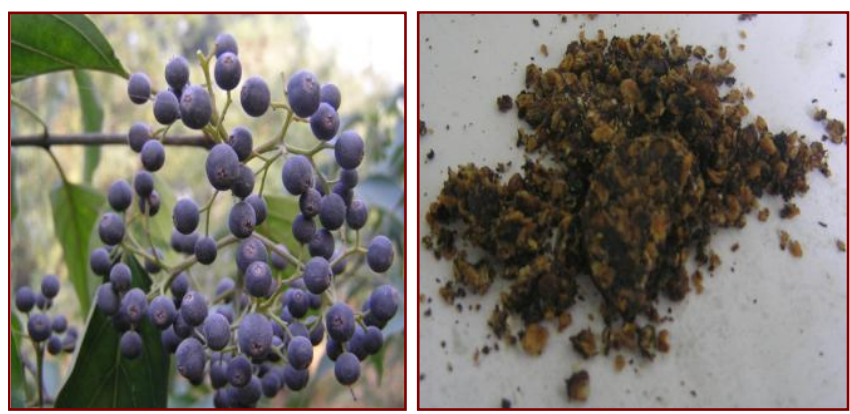

Figure 6. Swida wilsoniana fruits (left) and its meal (right)

\subsubsection{Physicochemical properties and fatty acid composition analysis of Swida wilsoniana fruits oil.}

For fresh fruits, timely dried is necessary, which is conducive to both the preservation for fruits and high quality control of crude oil. Table 2 illustrates the physicochemical property of swida wilsoniana oil and analysis of the major fatty acids by Gas chromatography. Newly pressed swida wilsoniana oil has a deep red color, which needs to be further refined before used as edible oil. Gas chromatography analysis showed that swida wilsoniana oil is a kind of high quality woody oil, which is rich in unsaturated fatty acid nearly of $72 \%$ altogether $29.83 \%$ oleic acid, $39.15 \%$ linoleic acid and $2.59 \%$ linolenic acid.

Table 2. Physicochemical property of Swida wilsoniana oil and Analysis of the major fatty acids

\begin{tabular}{|l|l|l|l|}
\hline program & index & unit & result \\
\hline \multirow{5}{*}{ property } & acid value & $\mathrm{mg} \mathrm{KOH} / \mathrm{g}$ & 1.27 \\
\cline { 2 - 4 } & $\begin{array}{l}\text { peroxide } \\
\text { value }\end{array}$ & $\mathrm{mmol} / \mathrm{Kg}$ & 7.6 \\
\cline { 2 - 4 } & color $(25.4)$ & -- & $\begin{array}{l}\mathrm{R}=40.0, \\
\text { Y=15.0, B=15.0 }\end{array}$ \\
\cline { 2 - 4 } & Iodine & $\mathrm{g} \mathrm{I}_{2} / 100 \mathrm{~g}$ & 104.48 \\
\cline { 2 - 4 } & $\begin{array}{l}\text { Saponification } \\
\text { value }\end{array}$ & $\mathrm{Mg} \mathrm{KOH} / \mathrm{g}$ & 199.04 \\
\hline \multirow{5}{*}{$\begin{array}{l}\text { Composition } \\
\text { fatty acids }\end{array}$} & $\mathrm{C}_{18} \mathrm{H}_{32} \mathrm{O}_{2}$ & $\%$ & 39.15 \\
\cline { 2 - 4 } & $\mathrm{C}_{18} \mathrm{H}_{34} \mathrm{O}_{2}$ & $\%$ & 29.83 \\
\cline { 2 - 4 } & $\mathrm{C}_{16} \mathrm{H}_{32} \mathrm{O}_{2}$ & $\%$ & 21.79 \\
\cline { 2 - 4 } & $\mathrm{C}_{18} \mathrm{H}_{30} \mathrm{O}_{2}$ & $\%$ & 2.59 \\
\cline { 2 - 4 } & $\mathrm{C}_{18} \mathrm{H}_{36} \mathrm{O}_{2}$ & $\%$ & 1.61 \\
\cline { 2 - 4 } & others & $\%$ & 5.03 \\
\hline
\end{tabular}

\section{CONCLUSIONS}

Swida wilsoniana is an important woody oil plant of which the whole fruits contain oils. Main contents of fruits from swida wilsoniana were analyzed through chemical means to 46 samples from different areas. These fruits have an average moisture content of about $8.19 \%$ after natural dried. The oil content is about $28.02 \%$ (dry basis) or more. The protein content is $7.25 \%$ (dry basis) and the cellulose content is about $14.18 \%$.

Through theoretical calculation and the onedimensional pressing device, the conditions of cold pressing process and performances of fruits from swida wilsoniana had been studied. The results show that swida wilsoniana fruits suffering natural dried are suitable for direct pressing, which guarantees a higher oil quality. The volume of fruits fed into pressing device had little effect on pressures of oil squeezed out, fruits crushed and critical compression, and the value of those pressures were 55.7 $\mathrm{MPa}, 71.5 \mathrm{MPa}$ and $80 \mathrm{MPa}$ individually. At 
the critical pressure of $80 \mathrm{MPa}$ and the compression ratio of 3.14 , residual oil of meal is $6.5 \%$.

Swida wilsoniana oil is a kind of high quality woody oil, which is rich in unsaturated fatty acid nearly of $72 \%$ altogether $29.83 \%$ oleic acid, $39.15 \%$ linoleic acid and $2.59 \%$ linolenic acid.

\section{REFERENCES}

[1] Cheng Xunyan(1990). Swida wilsoniana is a precious woody oil resource. biological and specialty precious, (6): 28.

[2] Yao Maohua, Zhang Liangbo, Xiang Zuheng, et al(2009). The progenitor constant of biodiesel raw material Swida wilsoniana. Hunan Forestry of science and technology, 36 (3): 45-46.

[3] Liang Yangzhen(1996). An oil plant worthy to be developed, Swida wilsoniana. Plant Journal, (2): 12.
[4] Li Shilong(2005). Research progress of double screw extruder home and abroad. China oil, 30 (12): 13-16.

[5] Ni Peide(2003). Oil processing technology. Beijing: Chemical Industry Press, 275-285.

[6] Xin Yaonian(2005). Idea and application area of cold press of oilseed. China oil, 30 (2): 20-22

[7] Li Changzhu, Xiao Zhihong, Liu Rukuan, et al(2012). The pressing performance of spiral cold pressing machine for fruits from Swida wilsoniana. Hunan forestry science and technology, 40 (2): 6-8.

[8] Li Jun(2012). Design of Small Cold Screw Press of Hard Core Oil and Study of Oil Squeezing Process. Central South University press.

[9] Li Changzhu, Xiao Zhihong, Liu Rukuan, et al (2013). A kind of pressing experiment device for plant oil. CN201320384392.7. China.

[10]Xiao Zhihong, Li Changzhu, Chen Jingzhen, etal(2009). Analysis of oil composition in different parts of Cornus wilsoniana Wanger. fruit. China oil, 34 (2): 72-74.

[11]Diao Hongsun(1985). Oilseeds pretreatment and pressing technology. Nanchang: Jiangxi science and Technology Press. 